\title{
Antagonistic Interactions Between Strains of Xanthomonas oryzae pv. oryzae
}

\author{
Christopher Dardick, Francisco Goes da Silva, Yuwei Shen, and Pamela Ronald
}

Department of Plant Pathology, University of California Davis, One Shields Avenue, Davis 95616.

Accepted for publication 15 January 2003.

\begin{abstract}
Dardick, C., da Silva, F. G., Shen, Y., and Ronald, P. 2003. Antagonistic interactions between strains of Xanthomonas oryzae pv. oryzae. Phytopathology 93:705-711.

The ability of some phytopathogenic bacterial strains to inhibit the growth of others in mixed infections has been well documented. Here we report that such antagonistic interactions occur between several wild-type strains of the rice bacterial blight pathogen Xanthomonas oryzae pv. oryzae. In mixed inoculations, a wild-type Philippine strain was found to inhibit the growth of a wild-type Korean strain. Furthermore, a nonpathogenic mutant of the Philippine strain maintained these antagonistic properties. Growth curve analysis indicated that both the wild-type Philippine strain and its nonpathogenic mutant inhibited the growth of the Korean strain

strains that were not affected by the nonpathogenic mutant were found to inhibit the growth of both the wild-type and mutant Philippine strains, indicating that antagonism is widespread and strain specific. The observed growth inhibition occurred only in planta and did not correlate with bacteriocin activity in vitro. Antagonistic interactions also were found to affect resistance $(R)$ gene-mediated resistance. The $R$ gene $X a 21$ was capable of protecting rice plants co-inoculated with nonantagonistic virulent and avirulent strains; however, when avirulent strains were coinoculated with virulent antagonistic strains, disease ensued. Taken together, these results indicate that $X$. oryzae pv. oryzae has evolved strategies to compete with rival strains in a fashion that allows virulent strains to evade $R$ gene-mediated protection even when avirulent strains are present in the inoculum.
\end{abstract} 2 days after infection and prior to the onset of disease symptoms. When mixed with the nonpathogenic mutant, 10 out of 18 diverse wild-type $X$. oryzae pv. oryzae strains did not cause disease. Conversely, three of the
Additional keywords: bacteriocin, resistance gene, type III secretion.
In rice fields, populations of the bacterial blight pathogen Xanthomonas oryzae pv. oryzae are diverse and dynamic. Multiple strains are often present in a given region with one or a small number of predominant strains. $X$. oryzae pv. oryzae population structure can be influenced by environmental changes such as seasonal variations and the presence of plant disease resistance $(R)$ genes in the planted rice cultivars $(1,2,13,14)$. Therefore, the success of individual strains depends on their interactions with the environment, hosts, and other rival strains.

Antagonistic interactions between closely related strains of both gram-negative and gram-positive bacteria often are influenced by the production of bacterial toxins termed bacteriocins. Bacteriocins compose a large family of toxins that include small peptides, proteins, phage-like particles, and, in some cases, multimeric protein complexes that are toxic to bacterial strains lacking specific immunity genes. Bacterial strains that secrete these toxins gain a selective advantage over susceptible strains, especially in nutrientpoor environments $(3,6)$. A number of $X$. oryzae pv. oryzae strains are known to exhibit bacteriocin activity. Sakthivel and Mew (18) showed that rice plants pretreated with nonpathogenic mutants of bacteriocin-producing strains displayed a marked reduction in the incidence of disease produced by bacteriocin-sensitive challenged strains. This form of cross-protection was effective in controlling bacterial blight disease in a strain-specific manner and demonstrated potential for biocontrol strategies.

Antagonism between strains of plant-pathogenic bacteria is not limited to the secretion of bacteriocins. A number of nonpathogenic bacterial mutants have been characterized that inhibit the

Corresponding author: P. Ronald; E-mail address: pcronald@ucdavis.edu

Publication no. P-2003-0408-02R

(C) 2003 The American Phytopathological Society spread of challenged wild-type strains. Several hypersensitive response and pathogenicity (Hrp) mutants from Erwinia, Pseudomonas, and Xanthomonas spp. that prevent disease by co-inoculated or challenge-inoculated parental pathogenic strains have been described (7,9,21). For Example, Erwinia amylovora strains containing mutations in the hrp cluster as well as genes involved in exopolysaccharide production have been shown to have varying levels of protective effects (21). Currently, the mechanisms of inhibition by these mutants remain unclear. However, a Ralstonia solanacearum $\mathrm{HrcV}$ mutant was found to prevent the spread of wild-type $R$. solanacearum strains in tomato by inhibiting colonization through the xylem (7). Thus, it appears that, in addition to serving as potential biocontrol agents, such strain-strain interactions may reveal important insights into the mechanisms of pathogenesis and disease.

Antagonism between $X$. oryzae pv. oryzae strains in planta has been implied or suggested by a few reports $(4,5,17)$. These reports have arisen from studies on the ability of specific resistance genes $(R)$ to confer resistance against avirulent and virulent $X$. oryzae pv. oryzae strains in mixed inoculations. Plants carrying $R$ genes recognize and respond to pathogens carrying corresponding avirulence (avr) genes (8). Once triggered, the ensuing defense responses not only block the growth of the challenging avirulent pathogen strain, but also restrict virulent strains lacking the specific $a v r$ gene. For example, mixed inoculation of the avirulent strain Pseudomonas syringae pv. tomato and the virulent strain $P$. syringae pv. maculicola on Arabidopsis plants containing the $R$ gene RPS2 result in restricted growth of both bacterial strains (5). Unexpectedly, in rice, Parry and Callow (16) found that mixing avirulent and virulent $X$. oryzae pv. oryzae strains resulted in disease irrespective of the presence of individual $R$ genes in the rice cultivars tested. Barton-Willis et al. (4) tested the ability of three rice $R$ genes (Xa10, $\mathrm{Xa4}$, and $\mathrm{Xa11}$ ) to restrict the growth of virulent strains when mixed with strains carrying the corresponding 
$a v r$ genes. They demonstrated that avirulent $X$. oryzae pv. oryzae strains grew slowly in mixed infections, whereas virulent strains grew normally and produced typical symptoms. These dynamics were shown to occur even in a rice cultivar susceptible to both $X$. oryzae pv. oryzae strains. Consequently, the authors hypothesized that competitive interactions between strains prevented avirulent strains from reaching a "threshold" number of bacteria necessary to trigger the resistance response.

Here we show that antagonism occurs between multiple $X$. oryzae pv. oryzae strains from several different countries in planta and that the interactions observed between strains in planta do not correlate with bacteriocin production in vitro. Furthermore, we found that these antagonistic interactions are capable of masking the resistance phenotype conferred by the rice $R$ gene $X a 21$. The results of these studies as well as the potential mechanisms and significance of $X$. oryzae pv. oryzae antagonism are discussed.

\section{MATERIALS AND METHODS}

$X$. oryzae pv. oryzae strains and sources. All wild-type $X$. oryzae pv. oryzae strains were obtained from J. Leach, Kansas State University, Manhattan, and S. H. Choi, Division of Plant Pathology, NIAST, Suwon, Korea. PXO99HrpC ${ }^{-}$was provided by F. White, Kansas State University, Manhattan (25). All strains were cultured on PSA (23) or NB (Difco Laboratories, Detroit) agar media at $30^{\circ} \mathrm{C}$ for $72 \mathrm{~h}$ unless otherwise specified. A rifampicin-resistant mutant of the Korean strain DY89031 was generated as described by Barton-Willis et al. (4). Briefly, strains were grown overnight in $\mathrm{NB}$ at $30^{\circ} \mathrm{C}$ in the presence of rifampicin at $25 \mu \mathrm{g} / \mathrm{ml}$ and plated on PSA plates containing the same concentration of antibiotic. Three days later, resulting colonies were isolated and inoculated on Taipei309 and TP309-Xa21 (a Taipei 309 transgenic line homozygous for $\mathrm{Xa21}$ ) plants to verify their virulence phenotype. These were further confirmed via bacterial growth curves (Fig. 1).

Plant materials and growth conditions. The $\mathrm{Xa21}$ transgenic line Taipei309-106-17-3-37 (TP309-Xa21) previously was constructed by Song et al. (20) in the Japonica-recipient cv. Taipei309 (20). Both TP309 and TP309-Xa21 plants were grown in a greenhouse for 6 weeks. Three days prior to inoculation, plants were moved to environmental growth chambers and maintained under the following conditions: $24^{\circ} \mathrm{C}$ and $90 \%$ humidity for $10 \mathrm{~h}$ without light and $28^{\circ} \mathrm{C}$ and $85 \%$ humidity for $14 \mathrm{~h}$ with light.

Plant inoculation. Plants were inoculated using the scissors clip method (12). Bacteria were scraped from PSA plates and

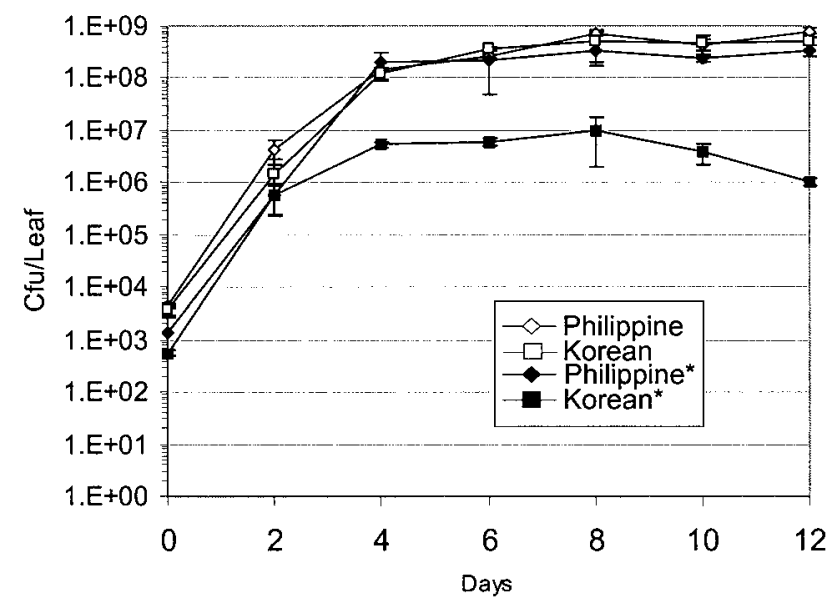

Fig. 1. Growth of the antagonistic Philippine Xanthomonas oryzae pv. oryzae strain PXO99 and the inhibited Korean strain DY89031 in single and mixed* (1:1 ratio) infections of Taipei309 plants. Mean CFU per leaf was calculated from at least three replicates, and the standard deviation for each value is shown. resuspended in water to an optical density at $600 \mathrm{~nm}\left(\mathrm{OD}_{600}\right)$ of $1.0\left(\approx 10^{9} \mathrm{CFU} / \mathrm{ml}\right)$. Bacteria were mixed at a ratio of $1: 1$ unless otherwise specified, and controls were mixed at a 1:1 ratio with water. Scissors were dipped into bacterial suspensions and used to clip $4 \mathrm{~cm}$ from the top of fully expanded leaves of 6- to 7-weekold plants. After 2 weeks, lesions forming on inoculated leaves were measured. Average lesion lengths were calculated based on the results from 10 to 15 leaves.

Bacterial accumulation and growth curves. Accumulation of $X$. oryzae pv. oryzae strains in inoculated plants was monitored at 14 days postinoculation or by growth curve analysis. Three inoculated leaves were assayed for each time point. Single leaves were removed from plants and ground, using a mortar and pestle, with $5 \mathrm{~g}$ of white quartz sand $(-50+70$ mesh, Sigma-Aldrich, St. Louis) for $15 \mathrm{~s}$. The leaf homogenate was diluted in $10 \mathrm{ml}$ of water and serial dilutions were plated on PSA plates supplemented with 5-azacytidine (PXO99A) at $20 \mu \mathrm{g} / \mathrm{ml}$, rifampicin (DY89031 ${ }^{\mathrm{rf}}$ ) at $50 \mu \mathrm{g} / \mathrm{ml}$, or kanamycin $\left(\mathrm{PXO} 9 \mathrm{HrpC}^{-}, \operatorname{rax} P^{-}\right.$, and $\left.\operatorname{rax} Q^{-}\right)$at $50 \mu \mathrm{g} / \mathrm{ml}$. Accumulation of $X$. oryzae pv. oryzae strains C21202, C21203, and C21303, which lack antibiotic resistance, was estimated by plating extracts on PSA without antibiotics and PSA supplemented with 5-azacytidine (PXO99A) or kanamycin $\left(\mathrm{PXO} 9 \mathrm{HrpC}^{-}\right)$. The number of colonies observed for the antibiotic-resistant strain was subtracted from those on plates without antibiotics. Bacterial colonies were counted and the number of CFU per leaf was rounded to the nearest logarithmic value. At least three replicates were assayed for each time point.

Bacteriocin assays. Bacteriocin assays were performed as described by Sakthivel and Mew (18). Bacterial strains were spotted onto NB agar plates supplemented with $5 \%$ sucrose and grown for $48 \mathrm{~h}$ at $22^{\circ} \mathrm{C}$. Subsequently, plates were exposed to chloroform for $2 \mathrm{~h}$ to arrest growth of colonies. Plates were overlaid with $100 \mu \mathrm{l}$ of indicator strains $\left(\mathrm{OD}_{600}=0.5\right)$ suspended in $4 \mathrm{ml}$ of $0.5 \%$ mol-

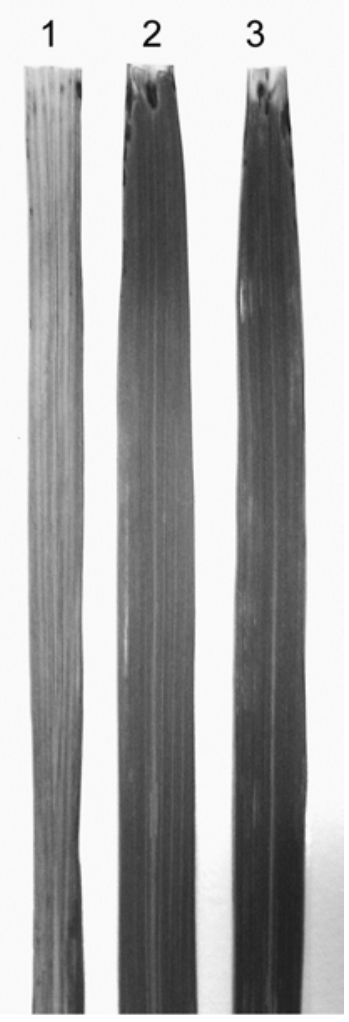

Fig. 2. The Korean strain DY89031 does not produce lesions when coinoculated with a nonpathogenic PXO99 mutant. Taipei309 leaves inoculated with the nonpathogenic Philippine mutant strain PXO99HrpC ${ }^{-}$and Korean strain DY89031. 1, DY89031; 2 PXO99HrpC ${ }^{-}$; 3, DY89031 and PXO99HrpC ${ }^{-}$mixed in a 1:1 ratio. Necrosis associated with lesions can be seen as light gray streaks on leaves. 
ten agarose (cooled to $45^{\circ} \mathrm{C}$ ). Bacteria were incubated for an additional $48 \mathrm{~h}$ at $22^{\circ} \mathrm{C}$. Inhibition zones were visualized as a halo surrounding individual colonies and measured.

\section{RESULTS}

In an attempt to further characterize the rice resistance gene $X a 21$, we wanted to determine whether $X a 21$ could provide protection against infection by co-inoculated virulent and avirulent $X$. oryzae pv. oryzae strains. The wild-type Philippine strain PXO99A (avirulent on Xa21 plants) was co-inoculated with a virulent Korean stain (DY89031 $1^{\text {rf }}$ ) on rice plants containing Xa21 (TP309-Xa21) or lacking the Xa21 transgene (TP309). At 14 days postinoculation, lesion lengths were measured. TP309 plants displayed long lesions $(15.3 \pm 1.7 \mathrm{~cm})$, similar to those inoculated with the avirulent Philippine strain $(14.2 \pm 3.1 \mathrm{~cm})$ and Korean strain $(18.6 \pm 3.7 \mathrm{~cm})$ alone. In contrast, TP309-Xa21 plants inoculated with PXO99 alone or in combination with the Korean strain developed only short lesions $(2.3 \pm 1.2$ and $2.1 \pm 1.3 \mathrm{~cm}$, respectively), characteristic of $\mathrm{Xa21}$ resistance, whereas those inoculated only with the Korean strain developed long lesions $(17.7 \pm 2.1 \mathrm{~cm})$. At 14 days postinoculation, bacterial growth was measured in infected leaves. Results indicated that, although long lesions were observed from mixed inoculations in TP309 plants, relatively little of the virulent Korean strain could be detected after 14 days. The Philippine strain reached $10^{6}$ to $10^{7} \mathrm{CFU} / \mathrm{leaf}$ in TP309-Xa21 and $10^{8}$ to $10^{9} \mathrm{CFU} /$ leaf in TP309 leaves; however, the Korean strain grew to only $10^{5}$ to $10^{6} \mathrm{CFU} / \mathrm{leaf}$ in both rice cultivars. This was in sharp contrast to the $10^{8}$ to $10^{9} \mathrm{CFU} / \mathrm{leaf}$ found in leaves inoculated with the Korean strain alone. Consequently, the effectiveness of the Xa21 resistance response in the mixed infection could not be assessed because the virulent Korean strain did not significantly grow even in the susceptible cultivar. Thus, we speculated that the avirulent Philippine strain PXO99A directly inhibited the growth of the virulent Korean strain DY89031 ${ }^{\text {rf }}$.

To further characterize the observed antagonistic interaction between the Philippine and Korean strains, bacterial growth curves were plotted to monitor the accumulation of each strain in mixed infections of TP309 plants (Fig. 1). The results showed, that when co-inoculated with the Korean strain, the Philippine strain grew to $10^{8}$ to $10^{9} \mathrm{CFU} /$ leaf after 4 to 6 days, the same levels as when inoculated alone. Although the Korean strain reached $10^{7} \mathrm{CFU} / \mathrm{leaf}$ at 6 days postinoculation, by 12 days postinoculation, bacterial numbers gradually dropped to $10^{6} \mathrm{CFU} /$ leaf. The resulting growth

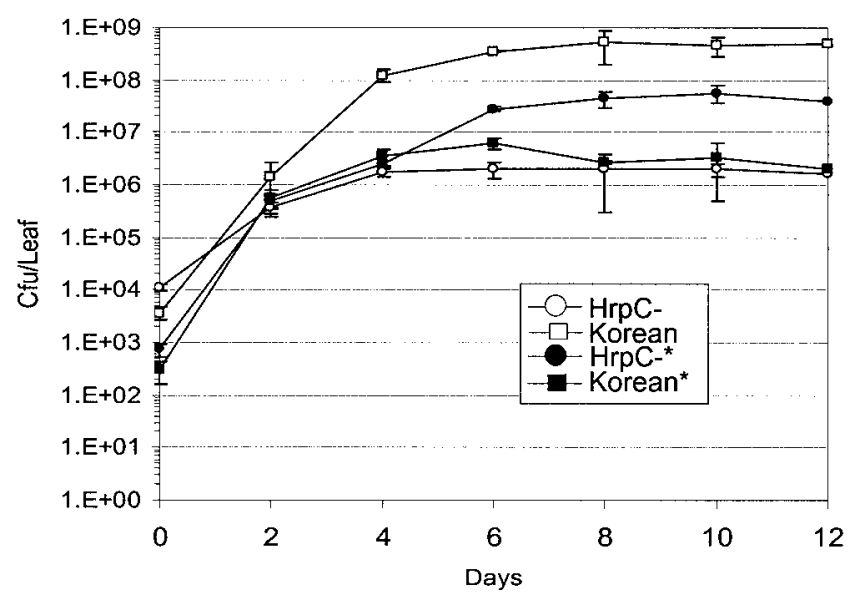

Fig. 3. A nonpathogenic Philippine strain inhibits the growth of Korean strain DY89031. Growth of the nonpathogenic Philippine mutant PXO99HrpC ${ }^{-}$and Korean strain DY89031 in single and mixed* (1:1 ratio) infections of Taipei309 plants. Mean CFU per leaf was calculated from at least three replicates, and the standard deviation for each value is shown. curves indicate that both strains grow at similar rates for the first 2 days, after which the growth of the Korean strain is significantly impaired.

A nonpathogenic PXO99A mutant maintains inhibitory activity. Nonpathogenic mutants of antagonistic strains have been shown to maintain inhibitory activity and serve as useful biocontrol agents. To determine whether such a mutant of Philippine strain PXO99A would maintain inhibitory activity toward the Korean strain, a previously characterized nonpathogenic PXO99A mutant, PXO99 $\mathrm{HrpC}^{-}$, was tested for the ability to inhibit the virulent Korean strain. This nonpathogenic mutant contains a mutation in the $h r p C$ gene which encodes an essential component for assembly of the Type III secretion apparatus (25). The mutant did not produce visible lesions or signs of disease when inoculated alone. However, it grew normally when co-inoculated with the wild-type parental Philippine strain PXO99A and did not alter the expected virulent and avirulent phenotypes on TP309 or TP309Xa21 plants, respectively. Samples taken from co-inoculated leaves indicated that both strains grew to the same levels in both rice lines by 14 days postinoculation: $10^{8}$ to $10^{9} \mathrm{CFU} /$ leaf in TP309 and $10^{5}$ to $10^{6} \mathrm{CFU} /$ leaf in TP309-Xa21. However, when the mutant strain was mixed with the virulent Korean strain DY89031 ${ }^{\text {rf }}$, no symptoms were observed on either TP309-Xa21 or TP309 plants and the resulting phenotype was identical to that of the mutant strain inoculated alone (Fig. 2). Growth curves showed that growth of the Korean strain was restricted in a fashion similar to that achieved by the wild-type Philippine strain (Fig. 3). At 4 days postinoculation, levels of the Korean strain were nearly 100 -fold less when co-inoculated with the mutant strain than when inoculated alone. Interestingly, levels of the mutant strain were at least 10-fold higher when co-inoculated with the Korean strain than when inoculated alone. Also, growth of the Korean strain when co-inoculated with the mutant strain behaved the same as the mutant strain inoculated alone.

To further characterize the ability of the nonpathogenic Philippine mutant to inhibit the Korean strain, we mixed the two strains at different ratios and inoculated the mixtures on TP309-Xa21 and TP309 plants (Fig. 4). Lesion development by the Korean strain was completely inhibited when mixed with the mutant up to ratios of 1:4 (PXO99HrpC ${ }^{-}$and DY89031 ${ }^{\text {rf }}$, respectively). At a ratio of 1:10, increased lesion lengths were observed; however, the lesions often were limited to the leaf margins. Dilution of 1 to 50 resulted in no detectable inhibition of the Korean strain and lesions were indistinguishable from those produced when the Korean strain was inoculated alone. These results demonstrate that the non-

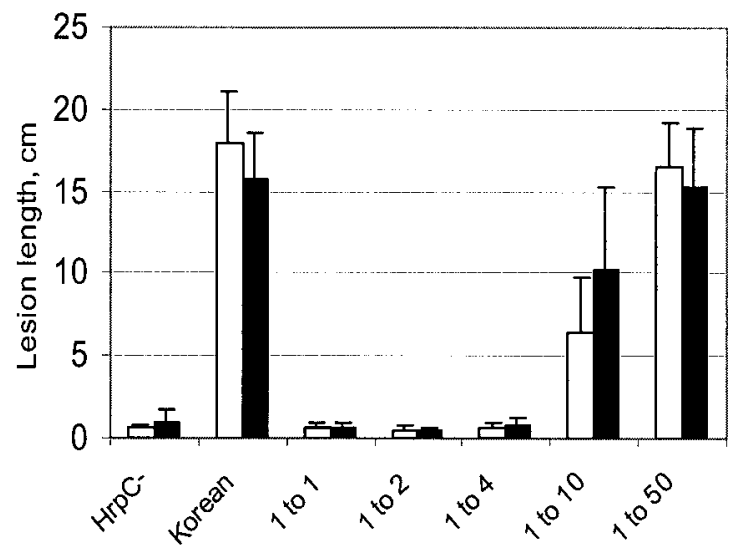

Fig. 4. Inhibition of Korean strain DY89031 by the nonpathogenic mutant PXO99HrpC - . Inoculations of DY89031 and PXO99HrpC ${ }^{-}$on Taipei309 (white bars) and $\mathrm{Xa21}$ transgenic line 106 (black bars) plants at different ratios. Ratios represent proportion of $\mathrm{PXO} 9 \mathrm{HrpC}^{-}$to the proportion of DY89031 in the inoculum. Data points represent mean lesion lengths measured from 8 to 12 leaves. Standard deviation is shown for each value. 
pathogenic Philippine strain inhibits the growth of the Korean strain when present even at relatively low ratios.

A nonpathogenic PXO99A mutant inhibits multiple wildtype $X$. oryzae pv. oryzae strains. The finding that a nonpathogenic PXO99A mutant retained the ability to restrict the growth of the Korean strain and prevent disease symptoms provided a visible phenotype to determine if the mutant strain could inhibit other wild-type X. oryzae pv. oryzae strains. $\mathrm{PXO} 99 \mathrm{HrpC}^{-}$was mixed pairwise at 1:1 ratios with $18 X$. oryzae pv. oryzae strains (representing isolates from four different countries) and inoculated on TP309 plants, which are susceptible to all X. oryzae pv. oryzae strains tested. The results are given in Table 1. The nonpathogenic mutant inhibited the spread of a number of different strains from India, Nepal, Korea, and the Philippines. Of the 18 strains tested, 10 showed no visible symptoms when co-inoculated with the mutant and 2 strains, A3857 and NXO195, gave reduced lesion lengths. However, five Philippine strains and one strain from $\mathrm{Ne}$ pal were not inhibited by the mutant strain. To further investigate

TABLE 1. Xanthomonas oryzae pv. oryzae strains from four different countries inoculated alone or in combination with PXO99 $\mathrm{AhrpC}^{-}$on TP309 rice plants

\begin{tabular}{llcc}
\hline & & \multicolumn{2}{c}{ Lesion length $^{\mathrm{a}}$} \\
\cline { 4 - 4 } Strain & Country & Alone & Mixed \\
\hline PXO61 & Philippines & $15.7 \pm 4.1$ & $0.6 \pm 0.4$ \\
PXO86 & Philippines & $14.5 \pm 3.8$ & $1.8 \pm 1.6$ \\
PXO112 & Philippines & $15.1 \pm 3.3$ & $2.1 \pm 0.9$ \\
A3842 & India & $15.3 \pm 3.2$ & $1.6 \pm 2.0$ \\
A3846 & India & $16.4 \pm 4.2$ & $1.4 \pm 1.1$ \\
DY89031 & Korea & $21.1 \pm 2.1$ & $0.6 \pm 0.4$ \\
KXO220 & Korea & $13.4 \pm 2.8$ & $1.3 \pm 1.2$ \\
KXO228 & Korea & $9.3 \pm 2.9$ & $1.4 \pm 0.8$ \\
KXO367 & Korea & $15.7 \pm 5.2$ & $2.4 \pm 0.9$ \\
NXO259 & Nepal & $12.7 \pm 1.4$ & $2.4 \pm 0.8$ \\
A3857 & India & $15.2 \pm 3.7$ & $4.1 \pm 3.1$ \\
NXO195 & Nepal & $12.3 \pm 2.3$ & $7.3 \pm 2.8$ \\
PXO69 & Philippines & $14.3 \pm 2.7$ & $14.5 \pm 2.4$ \\
PXO99 & Philippines & $17.3 \pm 3.1$ & $15.8 \pm 2.8$ \\
C21202 & Philippines & $14.5 \pm 4.0$ & $14.3 \pm 4.1$ \\
C21203 & Philippines & $17.1 \pm 0.8$ & $14.4 \pm 2.1$ \\
C21303 & Philippines & $15.4 \pm 3.2$ & $16.3 \pm 2.2$ \\
C2378 & Philippines & $12.7 \pm 3.6$ & $12.6 \pm 3.6$ \\
NXO101 & Nepal & $13.8 \pm 3.3$ & $14.7 \pm 2.1$ \\
\hline
\end{tabular}

${ }^{a}$ Values represent mean lesion lengths from 8 to 12 inoculated leaves \pm standard deviation. Strains are clustered according to the level of lesion length reduction.

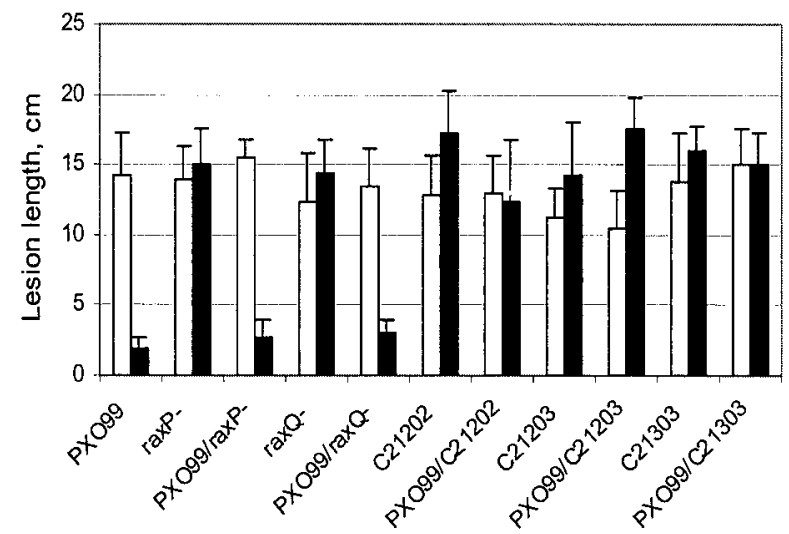

Fig. 5. Single and mixed inoculations of $\mathrm{PXO} 99$ with virulent Xanthomonas oryzae pv. oryzae strains on Taipei309 (white bars) and the Xa21 transgenic line 106 (black bars) plants. $\operatorname{RaxP}^{-}$and $\mathrm{rax}^{-}$are PXO99 mutants previously shown to lack avrXa21 activity and C21202, C21203, and C21303 are wildtype Philippine $X$. oryzae pv. oryzae strains virulent on Xa21 plants. Lesion lengths at 14 days postinoculation are shown for each strain inoculated alone and in mixture with PXO99 in a 1:1 ratio. Data points represent mean lesion lengths measured from 8 to 12 leaves \pm standard deviation. the basis for the lack of activity against these strains, leaves were sampled at 14 days postinoculation from TP309 plants co-inoculated with the mutant and each of three Philippine strains (C21202, C21203, or C21303). Sampled leaves contained $10^{4}, 10^{6}$, and $10^{5} \mathrm{CFU} /$ leaf of the nonpathogenic mutant, respectively, whereas all three wild-type Philippine strains grew to at least $10^{8} \mathrm{CFU} / \mathrm{leaf}$. The nonpathogenic mutant was found to reach $10^{8}$ to $10^{9} \mathrm{CFU} / \mathrm{leaf}$ when co-inoculated with the wild-type parental strain PXO99A; therefore, we hypothesized that the slow growth of the mutant in mixed infections with C21202, C21203, or C21303 was likely due to growth inhibition of the mutant by these strains rather than the inability of these strains to complement the highly conserved Type III secretion system lacking in the mutant.

PXO99A avirulence is dominant to $\operatorname{raxP}^{-}$and $\operatorname{rax} Q^{-}$virulence. Philippine strains C21202, C21203, and C21303 normally are virulent on $\mathrm{Xa} 21$ plants and potentially inhibited the nonpathogenic mutant $\mathrm{PXO} 99 \mathrm{HrpC}^{-}$; therefore, we tested whether these strain-strain interactions would have an affect on the ability of the avirulent wild-type strain, PXO99A, to elicit the $\mathrm{Xa21}$ resistance response. To first confirm that the $X a 21$ response was capable of restricting both avirulent and virulent strains in mixed inoculations, PXO99A was co-inoculated with two previously characterized virulent PXO99A mutants, $\operatorname{rax} P^{-}$and $\operatorname{rax} Q^{-}$. RaxP and $\operatorname{rax} Q$ were shown to encode enzymes that produce the activated sulfate forms APS and PAPS that serve as sulfate donors for sulfation of biomolecules by dedicated sulfotransferases (19). $X$. oryzae pv. oryzae strains containing mutations in $\operatorname{Rax} P$ or $\operatorname{Rax} Q$ give typical disease symptoms and are highly virulent on both non-Xa21- and Xa21-containing rice lines. Mixtures of PXO99A with $\operatorname{rax} P^{-}$or $\operatorname{rax} Q^{-}$resulted in avirulence on the $X a 21$ transgenic rice line TP309-Xa21, whereas a virulent phenotype was observed on TP309 plants (Fig. 5). At 14 days postinoculation, bacteria were extracted from inoculated leaves and plated on PSA plates containing the appropriate antibiotics to determine the relative growth of each strain. Leaves from mixed inoculations of the parental avirulent Philippine strain with $\operatorname{rax} P^{-}$or $\operatorname{rax} Q^{-}$contained the same concentrations of both $X$. oryzae pv. oryzae strains: $10^{6}$ to $10^{7} \mathrm{CFU} /$ leaf in TP309-Xa21 leaves and $10^{8}$ to $10^{8} \mathrm{CFU} / \mathrm{leaf}$ in TP309 leaves. These data indicate that the Xa21 resistance response triggered by wild-type PXO99A effectively prevents the growth of the virulent strains $\operatorname{rax} P^{-}$and $\operatorname{rax} Q^{-}$. Furthermore, dilution analysis of wild-type PXO99A with $\operatorname{raxP^{-}}$ revealed that, even at relatively low ratios, the avirulent strain was capable of eliciting the $\mathrm{Xa21}$ response (Fig. 6). At a ratio of 10:1 ( $\mathrm{raxP}^{-} /$ PXO99A), lesion lengths were substantially shorter than those produced by $\operatorname{raxP}^{-}$alone. Coincidently, lesion lengths increased as the ratio of the avirulent strain in the inoculum was reduced.

PXO99A avirulence is not dominant over C21202, C21203, and C21303 virulence. The avirulent Philippine strain PXO99A

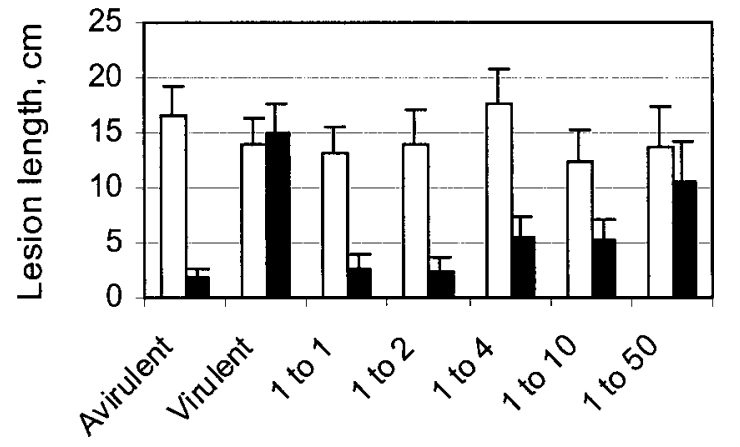

Fig. 6. Inoculations of avirulent wild-type PXO99 and the virulent mutant strain $\operatorname{raxP}^{-}$on Taipei309 (white bars) and the $\mathrm{Xa21}$ transgenic line 106 (black bars) plants at different ratios. Ratios represent proportion of PXO99 to that of $\operatorname{raxP}^{-}$in the inoculum. Data points represent mean lesion lengths measured from 8 to 12 leaves \pm standard deviation. 
was inoculated pair-wise in 1:1 proportions with three Philippine strains, C21202, C21203, and C21303, that were found to be both virulent on $\mathrm{Xa21}$ plants and uninhibited by the nonpathogenic mutant PXO99HrpC ${ }^{-}$. Mixed inoculation of wild-type PXO99A with each of the three virulent Philippine strains resulted in virulence on both TP309 and TP309-Xa21 (Fig. 5). Bacteria concentrations for each strain in inoculated leaves were measured after 14 days. For all three combinations, PXO99A was limited to $10^{4}$ to $10^{5} \mathrm{CFU} / \mathrm{leaf}$, whereas the virulent Philippine strains all reached at least $10^{8} \mathrm{CFU} /$ leaf in both TP309-Xa21 and TP309. These results show that growth of the avirulent Philippine strain PXO99 is inhibited by all three virulent Philippine strains in planta and that Xa21-mediated resistance was not observed when plants were coinoculated with mixtures of these strains.

No correlation between in vitro bacteriocin activity and in planta inhibition. We tested whether bacteriocin activity could account for the observed in planta inhibition between the $X$. oryzae pv. oryzae strains used in this study. A number of $X$. oryzae pv. oryzae strains were found to exhibit bacteriocin activity against indicator strains (Table 2). Although the nonpathogenic Philippine mutant inhibited 12 strains in in planta assays, no bacteriocin activity was found to be associated with this mutant strain or its wild-type parental strain PXO99A. In fact, both PXO99HrpC ${ }^{-}$ and PXO99A were susceptible to 11 different $X$. oryzae pv. oryzae strains. No consistent correlation was observed between bacteriocin activity or sensitivity and in planta inhibition. For example, Korean strain KXO220 inhibited 14 of 20 strains in bacteriocin assays, including $\mathrm{PXO} 9 \mathrm{HrpC}^{-}$, whereas lesion development by $\mathrm{KXO} 220$ was inhibited by $\mathrm{PXO}^{-} \mathrm{HrpC}^{-}$in planta. Although the three Philippine strains C21202, C21203, and C21303 inhibited PXO99A in planta, only C21202 and C21203 showed inhibitory activity toward PXO99A in vitro. Additional attempts were made to identify inhibitory compounds from infected tissues or in different medium conditions. Extracts from rice leaves infected with PXO99A showed no bacteriocin activity against Korean strain DY89031. Likewise, further bacteriocin assays performed on a variety of media conditions, including the addition of plant extracts and altered $\mathrm{pH}$, did not reveal any inhibitory activity between PXO99A and DY89031 (data not shown).

\section{DISCUSSION}

After co-inoculating X. oryzae pv. Philippine strain PXO99A or a nonpathogenic PXO99A mutant with many different $X$. oryzae pv. oryzae strains on susceptible rice plants, we found that, in most instances, competition between the strains resulted in reduced growth or disease symptoms in a strain-specific manner. PXO99A inhibited numerous strains from Korea, the Philippines, India, and Nepal, while at least three Philippine strains inhibited PXO99A. Although, the cause or causes of these antagonistic relationships remain unclear, some possible mechanisms can be explored. Bacteriocin-producing $X$. oryzae pv. oryzae strains have been well documented (18). However, in our in vitro studies, we were unable to identify any bacteriocin activity that correlated with the observed in planta inhibition. Despite this distinction, we cannot entirely rule out such a possibility because expression of bacteriocins often is induced under very specific conditions and sometimes can be difficult to identify (15).

The finding that PXO99A growth is sensitive to several strains in vitro but inhibits these strains in planta suggests the possibility of additional mechanisms. Based on growth curves of an inhibited Korean strain when co-inoculated with PXO99A or a nonpathogenic PXO99A mutant, our studies indicate that the Philippine strain does not interfere with growth of Korean strain until 2 days postinoculation. This time point is consistent with the stage at which the bacteria begin to spread through the xylem and cause disease symptoms (4). We speculate that, when co-inoculated with PXO99A, the Korean strain may grow normally in the initial infection site but does not spread through the xylem. This is implied from several findings. The inhibited Korean strain followed a growth pattern almost identical to that of the nonpathogenic PXO99A mutant inoculated alone. Also, co-inoculation with the nonpathogenic PXO99A mutant on susceptible rice plants resulted in few or no disease symptoms. Dilution assays showed that the ability of the Korean strain to cause disease on susceptible rice plants increased as the level of the mutant strain in the mixed inoculum was reduced. When the mutant was diluted with the Korean strain at a ratio of 1:10, respectively, the Korean strain escaped inhibition. The resulting lesions primarily occurred at the leaf margins, whereas the central vein and the surrounding tissue remained free of disease symptoms. This phenotype is reminiscent of an R. solanacearum Hrp mutant $\left(\mathrm{HrCV}^{-}\right)$which, when coinoculated with the parental pathogenic strain, blocks the spread of the pathogenic strain through xylem vessels in root tips (7). $H r c V^{-}$excludes the competing parental strain from the vascular bundles which it occupies while those which remain free of $\mathrm{HrCV}^{-}$ can become infected. Despite these parallels, deciphering the mechanism or mechanisms of $X$. oryzae pv. oryzae antagonism

TABLE 2. Bacteriocin activity between Xanthomonas oryzae pv. oryzae strains ${ }^{\mathrm{a}}$

\begin{tabular}{|c|c|c|c|c|c|c|c|c|c|c|c|c|c|c|c|c|c|c|c|c|}
\hline \multirow[b]{2}{*}{ Indicator strain } & \multicolumn{20}{|c|}{ Producing strain } \\
\hline & 1 & 2 & 3 & 4 & 5 & 6 & 7 & 8 & 9 & 10 & 11 & 12 & 13 & 14 & 15 & 16 & 17 & 18 & 19 & 20 \\
\hline 1. $\mathrm{HrpC}^{-}$ & - & - & + & ++ & - & + & ++ & ++ & - & ++ & + & - & - & ++ & - & - & - & + & + & + \\
\hline 2. PXO99 & - & - & + & ++ & - & + & ++ & ++ & - & ++ & + & - & - & ++ & - & - & - & + & + & + \\
\hline 3. PXO61 & - & - & - & + & + & - & ++ & + & + & + & - & - & - & ++ & - & - & - & + & + & + \\
\hline 4. PXO69 & - & - & - & - & - & - & + & + & + & - & - & - & - & ++ & - & - & - & - & - & + \\
\hline 5. PXO86 & - & - & - & - & - & - & - & - & - & - & - & - & - & ++ & - & - & - & - & - & - \\
\hline 6. PXO112 & - & - & - & - & - & - & - & - & - & - & - & - & - & ++ & - & - & - & - & - & + \\
\hline 7. C21202 & - & - & - & - & - & - & - & - & - & - & - & - & - & - & - & - & - & - & - & - \\
\hline 8. C21203 & - & - & - & - & - & - & - & - & - & - & - & - & - & - & - & - & - & - & - & - \\
\hline 9. C21303 & - & - & - & - & - & - & - & - & - & - & - & - & - & - & - & - & - & - & - & - \\
\hline 10. C2378 & - & - & - & - & - & - & - & - & - & - & - & - & - & - & - & - & - & - & - & - \\
\hline 11. A3846 & - & - & - & + & - & - & - & - & - & - & - & - & - & ++ & - & - & - & - & - & - \\
\hline 12. A3842 & - & - & - & + & - & - & - & - & - & - & - & - & - & ++ & - & - & - & - & - & - \\
\hline 13. A3857 & - & - & - & - & - & - & - & - & - & - & - & - & - & ++ & - & - & - & - & - & - \\
\hline 14. KXO220 & - & - & - & - & - & - & - & - & - & - & - & - & - & - & - & - & - & - & - & - \\
\hline 15. DY89031 & - & - & ++ & ++ & - & - & ++ & ++ & ++ & ++ & + & ++ & - & ++ & - & - & - & ++ & ++ & ++ \\
\hline 16. $\mathrm{KXO} 228$ & - & - & - & - & - & - & - & - & - & - & - & - & - & ++ & - & - & - & - & - & - \\
\hline 17. KXO367 & - & - & + & + & - & - & ++ & ++ & ++ & ++ & - & ++ & - & ++ & - & - & - & ++ & ++ & ++ \\
\hline 18. NXO101 & - & - & - & - & - & - & - & - & - & - & - & - & - & ++ & - & - & - & - & - & - \\
\hline 19. NXO195 & - & - & - & - & - & - & - & - & - & - & ++ & - & - & ++ & - & - & - & - & - & ++ \\
\hline 20. NXO259 & - & - & - & - & - & - & - & - & - & ++ & - & - & - & - & - & - & - & - & - & - \\
\hline
\end{tabular}

a - Denotes absence of inhibition zone, + denotes inhibition zone $<2 \mathrm{~mm}$ in diameter, and ++ denotes inhibition zone 2 to 4 mm in diameter. 
will require the cloning and characterization of the corresponding genes from antagonistic strains.

The successful use of plant $R$ genes in agriculture depends in large part on the behavior of complex pathogen populations over time. In this report, we also analyzed the effect of antagonistic interactions on elicitation of the Xa21-mediated defense response when faced with infection by mixed $X$. oryzae pv. oryzae populations. Using previously characterized mutants of Philippine strain PXO99A that are virulent on $\mathrm{Xa21}$ plants $\left(\operatorname{raxP} \mathrm{P}^{-}\right.$and $\left.\operatorname{rax}^{-}\right)(19)$, we were able to establish that the $X a 21$ response prevents the spread of these strains when co-inoculated with wild-type PXO99A. Dilution analysis further demonstrated that the level of protection conferred by $\mathrm{Xa21}$ correlated with the proportion of the avirulent strain in the inoculum. Previously, it had been shown that PXO99A accumulation in $\mathrm{Xa21}$ plants occurs normally until bacterial concentrations approach $10^{5}$ to $10^{6} \mathrm{CFU} / \mathrm{leaf}$; after which the $\mathrm{Xa21}$ response significantly slows further growth and prevents extended lesion formation $(20,24)$. When ratios greater than $1: 1$ (virulent/ avirulent) were inoculated, growth of the avirulent strain likely was delayed, resulting in some lesion formation by the abundant virulent $\operatorname{raxP}^{-}$strain. These results are consistent with those established for other $R$ genes, in which a critical concentration of avirulent bacteria must be achieved before defense responses are triggered (10).

In contrast, when the avirulent Philippine strain PXO99A was mixed with wild-type $X$. oryzae pv. oryzae strains known to be virulent on $\mathrm{Xa} 21$ plants, the anticipated resistant phenotypes were not observed. Although the virulent Korean strain did not cause disease when co-inoculated with the avirulent Philippine strain, it failed to significantly grow even when co-inoculated on control plants lacking $X a 21$. Three virulent Philippine strains antagonistic to PXO99A caused disease on Xa21 plants when mixed with the avirulent strain. In these cases, the antagonistic effects of these strains may have prevented the avirulent strain from reaching bacteria concentrations sufficient for eliciting the Xa21 response. Alternatively, interactions between these strains could disrupt $\mathrm{Xa} 21$ elicitation through interference between virulence or avirulence factors. Such interference previously has been reported. The avirulence gene avrPphC was found to disrupt the avirulence activity of a second avirulence gene, $\operatorname{avrPphF}$, in the interaction between $P$. syringae and bean (22). Although it remains unclear whether such interference occurs between PXO99A and the three virulent Philippine strains used in this study, we did find that the ability of PXO99A to inhibit the virulent Korean strain is not dependent on avirulence function because the virulent PXO99A $\operatorname{rax} P^{-}$and $\operatorname{rax} Q^{-}$mutants that lack avrXa21 activity maintained inhibitory activity (data not shown).

The population biology of $X$. oryzae pv. oryzae has been extensively studied and reviewed. Pathogen populations have been found to be dynamic and diverse and tend to be regionally dominated by specific races or strains $(1,2,13,14)$. A number of population shifts have been documented over the last 30 years in the Philippines and Korea. One case occurred in response to $R$ gene pressure after the widespread cultivation of $\mathrm{Xa4}$ rice plants in the Philippines. Interestingly, rather than existing avirulent race 1 strains simply losing avrXa4 activity, these strains were replaced by naturally occurring virulent race 2 strains from another geographic region (14). A more compelling instance occurred in Korea between 1989 and 1994, when the pathogen population shifted from strains avirulent on $\mathrm{Xa21}$ plants to strains virulent on $\mathrm{Xa21}$, even though Xa21 plants never had been cultivated in Korea (13). Although the forces driving population shifts are undoubtedly complex, antagonistic traits can play an important role. Jones et al. (11) noted a population shift of the tomato pathogen $X$. campestris pv. vesicatoria in Florida between 1991 and 1994, in which strain T3 rapidly replaced T1 as the dominant strain. This happened in the absence of $R$ gene selection and the authors demonstrated that the T3 strain was antagonistic to the T1 strain in mixed inoculations. Given the apparent widespread nature of $X$. oryzae pv. oryzae antagonism, this may also be an important factor contributing to $X$. oryzae pv. oryzae population shifts.

Further studies must be conducted to determine the relative importance of antagonistic interactions in rice fields and whether they contribute to $X$. oryzae pv. oryzae population dynamics or $R$ gene durability. In this study, relatively high bacterial concentrations were used for $X$. oryzae pv. oryzae inoculations $\left(10^{9} \mathrm{CFU} / \mathrm{ml}\right)$ and rice plants were maintained in controlled environmental conditions; whereas, in the field, infections likely initiate over a range of bacterial concentrations and conditions. Also, this report focused on infections of two strains simultaneously, whereas multiple strains may be present in any given field. The effects of such variables will be best resolved by carefully conducted greenhouse and field experiments. Irrespective of these experimental challenges, $X$. oryzae pv. oryzae antagonism highlights the ecological complexities of this bacterial pathogen and underscores the difficulties associated with predicting and maintaining $R$ gene durability.

\section{ACKNOWLEDGMENTS}

This work was funded by grants from NIH (GM55962) and NSF (9808913). C. Dardick was supported in part by an NIGMS MORE Institutional Research and Academic Career Development Award to University of California-Davis, grant number K12GM00679. We thank J. Leach and S. H. Choi for providing the wild-type $X$. oryzae pv. oryzae strains used in this study; and F. White for providing PXO99HrpC-; and S. Burdman, M.-S. Chern, J. S. Jeon, M. Campbell, and H. Fitzgerald for their valuable discussions and critical reading of the manuscript.

\section{LITERATURE CITED}

1. Adhikari, T. B., Vera Cruz, C. M., Zhang, Q., Nelson, R. J., Skinner, D. Z., Mew, T. W., and Leach, J. E. 1995. Genetic diversity of Xanthomonas oryzae pv. oryzae in Asia. Appl. Environ. Microbiol. 61:966-971.

2. Ardales, E. Y., Leung, H., Vera Cruz, C. M., Mew, T. W., Leach, J. E., and Nelson, R. J. 1996. Hierarchial analysis of spatial variation of the rice bacterial blight pathogen across diverse agroecosystems in the Philippines. Phytopathology 86:241-252.

3. Baba, T., and Schneewind, O. 1998. Instruments of microbial warfare: Bacteriocin synthesis, toxicity and immunity. Trends Microbiol. 6:66-71.

4. Barton-Willis, P. A., Roberts, P. D., Guo, A., and Leach, J. E. 1989. Growth dynamics of Xanthomonas campestris pv. oryzae in leaves of rice differential cultivars. Phytopathology 79:573-578.

5. Cameron, R. K., Dixon, R. A., and Lamb, C. J. 1994. Biologically induced systemic acquired-resistance in Arabidopsis thaliana. Plant J. 5:715-725.

6. Ennahar, S., Toshihiro, S., Sonomoto, K., and Ishizaki, A. 2000. Class IIa bacteriocins: Biosynthesis, structure and activity. FEMS Microbiol. Rev. 24:85-106.

7. Etchebar, C., Trigalet-Demery, D., Gijsegem, F., Vasse, J., and Trigalet, A. 1998. Xylem colonization by an $\mathrm{HcrV}^{-}$mutant of Ralstonia solanacearum is a key factor for the efficient biological control of tomato bacterial wilt. Mol. Plant-Microbe Interact. 11:869-877.

8. Flor, H. H. 1971. Current status of the gene-for-gene concept. Ann. Phytopathol. 28:275-296.

9. Frey, P., Prior, P., Marie, C., Kotoujansky, A., Trigalet-Demery, D., and Trigalet, A. 1994. Hrp ${ }^{-}$mutants of Pseudomonas solanacearum as potential biocontrol agents of tomato bacterial wilt. Appl. Environ. Microbiol. 60:3175-3181.

10. Goodman, R. N., Kiraly, Z., and Wood, K. R. 1986. Resistance to infection. Pages 379-382 in: The Biochemistry and Physiology of Plant Disease. University of Missouri Press, Columbia.

11. Jones, J. B., Bouzar, H., Somodi, G. C., Stall, R. E., Pernezny, K., ElMorsy, G., and Scott, J. W. 1998. Evidence for the preemptive nature of tomato race 3 of Xanthomonas campestris pv. vesicatoria in Florida. Phytopathology 88:33-38.

12. Kauffman, H. E., Reddy, A. P. K., Hsieh, S. P. V., and Marca, S. D. 1973. An improved technique for evaluation of resistance of rice varieties to Xanthomonas oryzae. Plant Dis. Rep. 57:537-541.

13. Lee, S. W., Choi, S. H., Han, S. S., Lee, D. G., and Lee, B. Y. 1999. Distribution of Xanthomonas oryzae pv. oryzae strains virulent to Xa21 in Korea. Phytopathology 89:928-933.

14. Mew, T. W., Vera-Cruz, C. M., and Medalla, E. S. 1992. Changes in race 
frequency of Xanthomonas oryzae pv. oryzae in response to rice cultivars planted in the Philippines. Plant Dis. 76:1029-1032.

15. Parente, E., and Ricciardi, A. 1999. Production, recovery and purification of bacteriocins from lactic acid bacteria. Appl. Microbiol. Biotechnol. 52:628-638.

16. Parry, R. W. H., and Callow, J. A. 1986. The dynamics of homologous and heterologous interactions between rice and strains of Xanthomonas campestris. Plant Pathol. 35:380-389.

17. Reddy, A. P. K., and Kauffman, H. E. 1974. Population studies of mixed inoculum of Xanthomonas oryzae in susceptible and resistant varieties of rice. Ann. Phytopathol. Soc. Jpn. 40:93-97.

18. Sakthivel, N., and Mew, T. W. 1991. Efficacy of bacteriocinogenic strains of Xanthomonas oryzae pv. oryzae on the incidence of bacterial blight disease of rice (Oryza sativa L.). Can. J. Microbiol. 37:764-768.

19. Shen Y, Sharma P, Silva F, and Ronald P. C. 2002. The Xanthomonas oryzae pv. oryzae $\operatorname{raxP}$ and $\operatorname{rax} Q$ genes encode an ATP sulfurylase and APS kinase that are required for AvrXa21 avirulence activity. Mol. Microbiol. 14:204-213.

20. Song, W.-Y., Wang, G.-L., Chen, L.-L., Kim, H.-S., Pi, L.-Y., Holsten, T., Gardner, J., Wang, B., Zhai, W.-X., Zhu, L.-H., Fauquet, C., and Ronald,
P. C. 1995. A receptor kinase-like protein encoded by the rice disease resistance gene, Xa21. Science 270:1804-1806.

21. Tharaud, M., Laurent, J., Faize, M., and Paulin, J. P. 1997. Fire blight protection with avirulent mutants of Erwinia amylovora. Microbiology 143:625-632.

22. Tsiamis, G., Mansfield, J. W., Hockenhull, R., Jackson, R. W., Sesma, A., Athanassopoulos, E., Bennett, M. A., Stevens, C., Vivian, A., Taylor, J. D., and Murillo, J. 2000. Cultivar-specific avirulence and virulence functions assigned to avrPphF in Pseudomonas syringae pv. phaseolicola, the cause of bean halo-blight disease. EMBO J. 19:3204-3214.

23. Tsuchiya, K., Mew, T. W., and Wakimoto, S. 1982. Bacteriological and pathological characteristics of wild types and induced mutants of Xanthomonas campestris pv. oryzae. Phytopathology 72:43-46.

24. Wang, G.-L., Ruan, D.-L., Song, W.-Y., Sideris, S., Chen, L., Pi, L.-Y., Zhang, S., Zhang, Z., Fauquet, C., Gaut, B. S., and Ronald, P. C. 1998. $X a 21 D$ encodes a receptor-like molecule with a leucine-rich repeat domain that determines race-specific recognition and is subjected to adaptive evolution. Plant Cell 10:765-779.

25. Zhu, W., Magbanua, M. M., and White, F. F. 2000. Identification of two novel $h_{r p}$-associated genes in the hrp gene cluster of Xanthomonas oryzae pv. oryzae. J. Bacteriol. 182:1844-1853. 